\title{
DEVELOPMENT OF A NEW STABILITY INDICATING RP-HPLC METHOD FOR SIMULTANEOUS ESTIMATION OF EPALRESTAT AND PREGABALIN AND ITS VALIDATION AS PER INTERNATIONAL CONFERENCE ON HARMONIZATION GUIDELINES
}

\author{
SWAPNA GODAY ${ }^{*}$, ABDUL RAHAMAN SK ${ }^{2}$, PRAMEELARANI ${ }^{3}$ \\ ${ }^{1}$ Department of Pharmacy, Nirmala College of Pharmacy and Research Scholar, JNTUK, Kakinada, Andhra Pradesh, India. ${ }^{2}$ Department of \\ Pharmaceutical Analysis, Nirmala College of pharmacy, Atmakur, Mangalagiri, Andhra Pradesh, India. ${ }^{3}$ Department of pharmaceutics, University \\ College of Pharmaceutical Sciences, Acharya Nagarjuna University, Guntur, Andhra Pradesh, India. Email: swapna.goday.gs@gmail.com
}

Received: 26 August 2017, Revised and Accepted: 07 February 2018

ABSTRACT

Objective: The present study was aimed to develop a novel, simple, rapid, accurate, stability-indicating reversed-phase high-performance liquid chromatography method, and validate for the simultaneous estimation of epalrestat and pregabalin in bulk and dosage form.

Methods: The chromatographic separation was performed on $\mathrm{c}_{18}$ column discovery ( $250 \mathrm{~mm} \times 4.6 \mathrm{~mm}, 5 \mu$ particle size) the optimized mobile phase consists of $0.01 \mathrm{~m}$ potassium dihydrogen phosphate buffer: Methanol $(25: 75 \% \mathrm{v} / \mathrm{v})$ with a flow rate of $1.0 \mathrm{ml} / \mathrm{min}$ and ultraviolet (UV) detection at $226 \mathrm{~nm}$.

Results: The chromatographic condition, retention time was $2.2 \mathrm{~min}$ (pregabalin), $2.8 \mathrm{~min}$ (epalrestat). Stress testing was performed in accordance with an International Conference on Harmonization (ICH) Q1A R2 guidelines. The method was validated as per ICH Q2 R1 guidelines. Linearity range was 30-180 ppm (epalrestat), 15-90 ppm (pregabalin), accuracy was in the range of $98.14-100.43 \%$ for both the drugs. Precision was $0.2 \%$ and $0.3 \%$ for epalrestat and pregabalin. Limit of detection and limit of quantification are $0.21 \mu \mathrm{g} / \mathrm{ml}$ and $0.65 \mu \mathrm{g} / \mathrm{ml}$ for epalrestat and $0.08 \mu \mathrm{g} / \mathrm{ml}$ and $0.25 \mu \mathrm{g} / \mathrm{ml}$ for pregabalin.

Conclusion: The method developed is more sensitive, accurate, and precise than the methods reported earlier. Retention time and runtime were also less, and hence, the method is economical. When applied for tablet assay, drug content was within 100.06-100.22\% of the labeled content. Forced degradation studies indicated the suitability of the method for stability studies. The proposed method can be used for routine determination of epalrestat and pregabalin.

Keywords: Epalrestat, Pregabalin, Reversed-phase high-performance liquid chromatography, Stability-indicating, Validation.

(c) 2018 The Authors. Published by Innovare Academic Sciences Pvt Ltd. This is an open access article under the CC BY license (http://creativecommons. org/licenses/by/4. 0/) DOI: http://dx.doi.org/10.22159/ajpcr.2018.v11i5.22256

\section{INTRODUCTION}

Epalrestat is a carboxylic acid derivative and a non-competitive and reversible aldose reductase inhibitor used for the treatment of diabetic neuropathy, which is one of the most common long-term complications in patients with diabetes mellitus (DM) [1]. Chemical name is 5-[(z, e)$\beta$-metylcinnamylidene]-4-oxo-2-tioxo-3-tiazolidineacetic acid [2]. Fig. 1 pregabalin is used for treating pain caused by neurologic diseases such as post-herpetic neuralgia as well as seizures. It also is used for treating fibromyalgia [3]. Chemical name is (3s)-3-(aminomethyl)-5methylhexanoic acid [4]. Fig. 2 pregabalin works in different ways in epilepsy it stops seizures by reducing the abnormal electrical activity in the brain with nerve pain it blocks pain by interfering with pain messages traveling through the brain and down the spine in anxiety it stops your brain from releasing the chemicals that make you feel anxious [5]. Epalrestat suppresses accumulation of sorbitol in nerve by inhibiting aldose reductase and relieves numbness or pain of the hands and feet and leg cramp, which induced by diabetic peripheral neuropathy [6]. Peripheral neuropathy is one of the most common and disabling longterm complications of DM. Diabetic neuropathy is the condition, either clinically evident or subclinical, that occurs in DM cases in the absence of other causes of peripheral neuropathy. DM is a chronic metabolic disorder manifested in the form of hyperglycemia as a consequence of a defect in insulin secretion and/or insulin action along with an imbalance in the metabolism of carbohydrates, fats, and proteins [7]. Diabetic nephropathy (DN) will affect approximately $30 \%$ of all patients with diabetes. DN is one of the most common microvascular complications of diabetes defined as a rise in urinary albumin excretion rate, often associated with an increase in blood pressure, but without evidence of other causes of renal disease [8]. Literature survey revealed that reversed-phase high-performance liquid chromatography (RP-HPLC) [9-14] has been reported for the estimation of epalrestat and pregabalin. The method was optimised by ammonium acetate buffer and acetonitrile for the simultaneous estimation of epalrestat and pregabalin [10]. The patients with diabetic nephropathy were divided into groups and multicentered study was conducted by epalrestst and methylcobalamine [9]. The gradient programme was used for chromatographic seperation using mobile phase as potassium dihydrogen phosphate and acetonitrile. The method was developed by phosphate buffer and acetonitrile with $\mathrm{pH}$ 6.9 using photodiode array detector[11]. Pregabalin was determined using precolumn derivatisation technique with uv detector using human plasma [12]. For the determination of pregabalin RP-HPLC method was developed using isocratic mode for chromatographic seperation followed by stability studies [13]. simultaneous determination of pregabalin and methylcobalamin was succesfully analyzed in bulk drug and marketed formulation using RP-HPLC method [14]. A stability indicating method accurately measures the active ingredient without the interference from degradation products, process impurities [15]. According to International Conference on Harmonization (ICH) guideline [16], the guidelines explicitly require the conduct of forced degradation studies under a variety of conditions such as $\mathrm{PH}$, light, oxidation, and dry heat and separation of drug from degradation products [17]. To the best of our knowledge, only one stability indicating RP-HPLC method has been 
reported for epalrestat and pregabalin. The present work involves stress degradation as per ICH Q1 A (R2) and Q1B [16,17] for the developing new, simple, sensitive stability indicating RP-HPLC method; the method was validated as per the ICH guidelines Q2 R1 [18]. The reported methods were not cost effective due to use costly solvents and in some methods, the retention time was found to be more. Hence, in the present work a novel, simple, precise, sensitive, and stability indicating method was developed using low-cost solvent potassium dihydrogen phosphate buffer:Methanol $(25: 75 \% \mathrm{v} / \mathrm{v})$, detected using a photodiode array detector which was highly sensitive to detect at a lower concentration. The developed method was used for estimation epalrestat and pregabalin in the pharmaceutical dosage form.

\section{MATERIALS AND METHODS}

\section{Chemicals}

The reagents used in this work were methanol (HPLC grade-Merck Life sciences Pvt., Ltd., Mumbai, India), orthophosphoric acid, (Thermo Fisher Scientific, Pvt., Ltd., Mumbai, India), $\mathrm{HCl}$ (AR), NaoH (AR), and hydrogen peroxide $(85 \% \mathrm{w} / \mathrm{v})$ (AR), which were procured from Merck life Sciences, Pvt., Ltd., Mumbai, India), HPLC grade water (Lichrosolv, Merck life sciences, Pvt., Ltd., Mumbai, India). The working standards of epalrestat and pregabalin were procured from standard Laboratories Hyderabad., India. Pre aldonil (Zydus) tablet containing epalrestat $150 \mathrm{mg}$ and pregabalin $75 \mathrm{mg}$ were procured from local market.

\section{Instrumentation}

The instruments used in the study were electronic balance (sigma 200), digital pH meter (systronics), sonicator (cyber labs), ultraviolet (UV) UV-visible spectrophotometer (thermo scientific), and HPLC (waters alliance, empower 2 software) Detector (PDA).

\section{Chromatographic conditions}

HPLC instrument waters alliance with empower software, PDA detector. Sample name prealdonil (epalrestat, pregabalin), the mobile phase used was prepared $0.01 \mathrm{M}$ by $1.36 \mathrm{~g}$ of potassium dihydrogen phosphate was taken in a $1000 \mathrm{ml}$ of volumetric flask add about $900 \mathrm{ml}$ of purified water added and degas to sonicate and finally make up the volume with water. $\mathrm{PH}$ adjusted to 4.5 with orthophosphoric acid, respectively. Before use the mobile phase is filtered through $0.45 \mu \mathrm{m}$ membrane filter and degassed, the mobile phase ratio of phosphate buffer and methanol is in the ratio of $25: 75 \% \mathrm{v} / \mathrm{v}$, respectively. Mobile phase flow

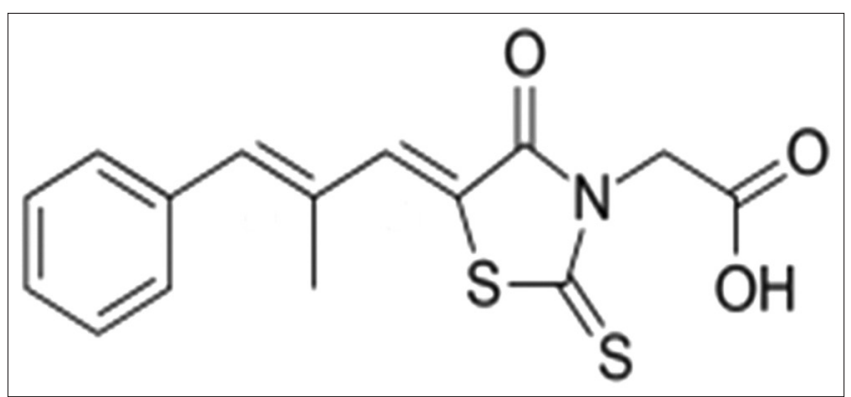

Fig. 1: Molecular structure epalrestat

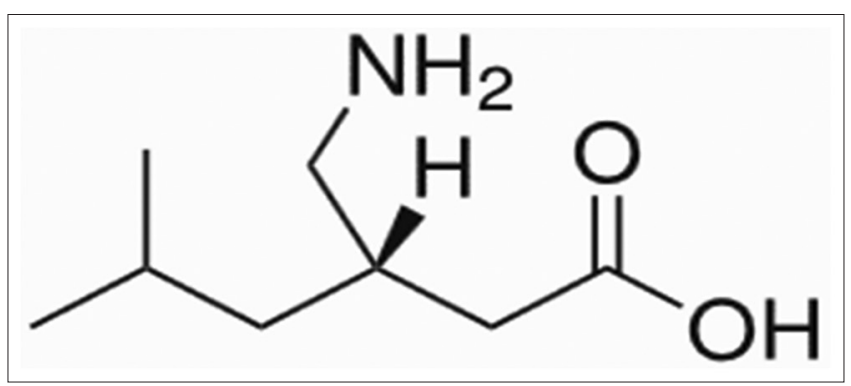

Fig. 2: Molecular structure pregabalin rate was maintained at $1.0 \mathrm{ml} / \mathrm{min}$, eluents were monitored at $226 \mathrm{~nm}$. Separation was performed on column Discovery C18 $250 \times 4.6 \mathrm{~mm}$, $5 \mu$, at temperature $25^{\circ} \mathrm{C}$, injection volume $10 \mu \mathrm{l}$, runtime of $6 \mathrm{~min}$. The diluent used is a mixture of water and methanol in the ratio of 50:50 v/v. The optimized chromatographic conditions are shown in Table 1.

\section{Method development}

Preparation of standard solutions

Stock solution of epalrestat and pregabalin

Accurately weighed and transferred $15 \mathrm{mg}$ and $7.5 \mathrm{mg}$ of epalrestat and pregabalin working standards into a $10 \mathrm{ml}$ clean dry volumetric flask, respectively, add $7 \mathrm{ml}$ of diluent, sonicated for $20 \mathrm{~min}$ and make up to the final volume with diluents to get a concentration of $150 \mu \mathrm{g} / \mathrm{ml}$ epalrestat $75 \mu \mathrm{g} / \mathrm{ml}$ pregabalin.

Working standard solution

From the above stock solutions, working standard was prepared by taking $1 \mathrm{ml}$ and pipetted out into a $10 \mathrm{ml}$ volumetric flask to get a concentration of $15 \mu \mathrm{g} / \mathrm{ml}$ of epalrestat and $7.5 \mu \mathrm{g} / \mathrm{ml}$ of pregabalin then make up to the final volume with diluent.

Preparation of sample solutions of epalrestat and pregabalin Twenty tablets were weighed and calculate the average weight of each tablet then the weight equivalent to one tablet epalrestat $150 \mathrm{mg}$ and pregabalin $75 \mathrm{mg}$ was transferred into a $10 \mathrm{ml}$ volumetric flask, $7 \mathrm{ml}$ of diluent added and sonicated for $30 \mathrm{~min}$, further, the volume made up with diluent and filtered. From the filtered solution $1 \mathrm{ml}$ was pipetted out into a $10 \mathrm{ml}$ volumetric flask and made up to $10 \mathrm{ml}$ with diluents. Filter through $0.45 \mu$ Nylon syringe filter.

Selection of wavelength

Ideal wavelength is the one that gives good response for the drugs that are to be detected. Overlay UV spectra of both the drugs showed that epalrestat and pregabalin absorbed appreciably at $226 \mathrm{~nm}$, so detection was carried out at $226 \mathrm{~nm}$ Fig. 3. A standard chromatogram of pregabalinof RT2.2 min and epalrestat 2.8 min Fig. 4.

Preparation of calibration curve

Calibration curve is prepared by appropriate aliquots of $0.2 \mathrm{ml}, 0.4 \mathrm{ml}$, $0.6,0.8 \mathrm{ml}, 1 \mathrm{ml}$, and $1.2 \mathrm{ml}$ from working standard solution of epalrestat

Table 1: Optimized chromatographic conditions of epalrestat and pregabalin

\begin{tabular}{ll}
\hline Parameters & Conditions \\
\hline Stationary phase (column) & Discovery C18 250×4.6 mm, $5 \mu$ \\
Mobile phase & Potassium dihydrogen phosphate: \\
& methanol $(25: 75)$ \\
Flow rate $(\mathrm{ml} / \mathrm{min})$ & 1.0 \\
Runtime $(\mathrm{min})$ & 6.0 \\
Column temperature & Ambient temperature \\
Volume of injection $(\mu \mathrm{l})$ & 10 \\
Detection wavelength $(\mathrm{nm})$ & 226 \\
Retention time $(\mathrm{min})$ & Pregabalin RT 2.2 and RT epalrestat \\
& 2.8 \\
\hline
\end{tabular}

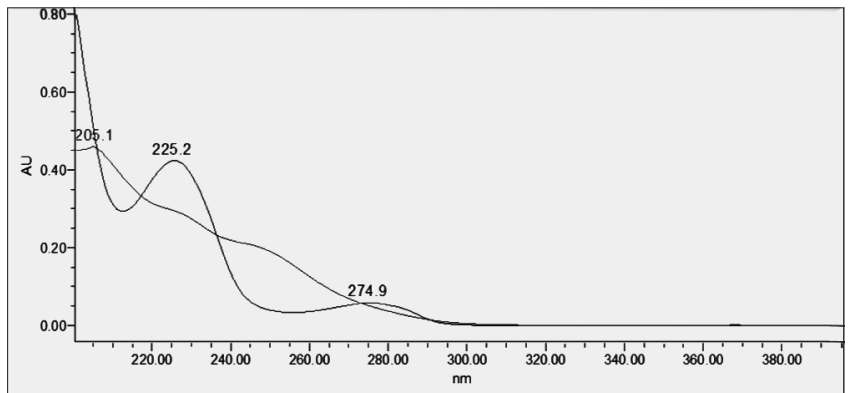

Fig. 3: Overlay spectra of epalrestat and pregabalin $\lambda \max 226 \mathrm{~nm}$ 


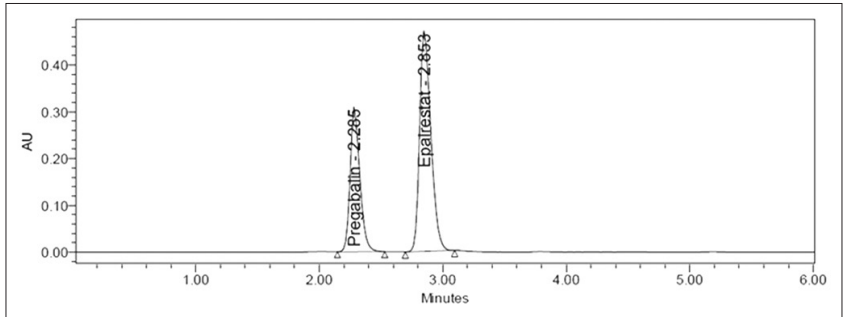

Fig. 4: Representative chromatogram of standard pregabalin of RT 2.2 and RT of epalrestat 2.8

and pregabalin, in $10 \mathrm{ml}$ volumetric flask and dilute to mark with diluent to give a concentration range of 30-180 ppm for epalrestat and 15$90 \mathrm{ppm}$ for pregabalin. The data of peak area versus drug concentration were treated by linear least square regression analysis. The standard curve is evaluated for linearity by its coefficient of determination $\left(R^{2}\right)$.

\section{Method validation}

The developed method was validated by evaluating linearity, precision, specificity, accuracy, limit of detection (LOD), limit of quantification (LOQ), robustness, ruggedness, assay, forced degradation studies, and solution stability. The coefficient of variation and relative errors of $<2 \%$ are considered acceptable except for LOQ for which these values were established at $2 \%$

Linearity

A stock solution of $150 \mu \mathrm{g} / \mathrm{ml}$ epalrestat $75 \mu \mathrm{g} / \mathrm{ml}$ pregabalin was prepared with diluent. Working standard was prepared by taking $1 \mathrm{ml}$ and pipetted out into a $10 \mathrm{ml}$ volumetric flask to get a concentration of $15 \mu \mathrm{g} / \mathrm{ml}$ of epalrestat and $7.5 \mu \mathrm{g} / \mathrm{ml}$ of pregabalin then make up to the final volume with diluents. From it standard calibration curve is prepared with six calibrators over a concentration range of 30-180 ppm for epalrestat and 15-90 ppm for pregabalin and injected into HPLC. The data of peak area versus drug concentration were treated by linear least square regression analysis. The standard curve is evaluated for linearity.

Accuracy

To determine the accuracy of method recovery studies were planned and carried out by standard addition method at different levels of $50 \%, 100 \%$, and $150 \%$ and then comparing the difference between the spiked value and actual found value.

Precision

The precision of the assay was studied with respect to both method precision. The system precision was ascertained from the peak area obtained by actual determination of six replicate injections of freshly prepared solution on the same equipment on the same day. System precision for epalrestat was performed at a concentration $150 \mathrm{ppm}$ and pregabalin at concentration of $75 \mathrm{ppmsolution}$. The precision of the assay was also determined in terms of intra- and inter-day variation in the peak area of the drug solution was calculated in terms of relative standard deviation (RSD).

\section{Robustness}

Robustness of the proposed method for epalrestat and pregabalin was carried out by the slight variation in flow rate, mobile phase composition, column temperature the analytical parameter on the retention time of drugs was examined. The method is found to be robust with no change in retention time.

Ruggedness

The test solution is prepared as per test method and injected under variable conditions ruggedness of the method was studied by different analysts.

Detection limit and quantification limit

The LOD and LOQ were established based on the calibration curve parameters according to the following formulas:
LOD=3.3 SD/slope

$\mathrm{LOQ}=10 \mathrm{SD} /$ slope.

Where $\sigma$ is the standard deviation of y-intercept of regression line, and $\mathrm{s}$ is the slope of calibration curve.

Specificity

Specificity of a method can be defined as the absence of any interference at retention times of peaks of interest and was evaluated by observing the chromatograms of blank samples and comparison with a placebo solution.

\section{Assay}

The weight equivalent to one tablet was transferred into a $10 \mathrm{ml}$ volumetric flask, diluent added and sonicated for $30 \mathrm{~min}$, further, the volume made up with diluent and filtered. From the filtered solution $1 \mathrm{ml}$ was pipetted out into a $10 \mathrm{ml}$ volumetric flask and made up to $10 \mathrm{ml}$ with diluent. Six injections of the sample were injected, the average mean peak area responses, SD, \%RSD, and \% assay was calculated.

\section{Forced degradation studies}

The assay method was used to test the drug stability demonstrated through forced degradation studies conducted for the sample under various stress conditions. Stress degradation studies were carried out for acid hydrolysis $\left(2 \mathrm{~N} \mathrm{Hcl} \mathrm{heated} \mathrm{for} 30 \mathrm{~min}\right.$ at $60^{\circ} \mathrm{C}$ ), alkali hydrolysis (2 $\mathrm{NaOH}$ heated for $30 \mathrm{~min}$ at $60^{\circ} \mathrm{C}$ ), oxidative degradation $(20 \%$ $\mathrm{H}_{2} \mathrm{O}_{2}$ heated at $60^{\circ} \mathrm{C}$ for $30 \mathrm{~min}$ ), and thermal degradation (samples were placed in an oven at $105^{\circ} \mathrm{C}$ for $6 \mathrm{~h}$ ). For photolytic stress studies, samples were exposed to UV light in UV chamber for $1 \mathrm{~h}$.

\section{Hydrolytic degradation}

Hydrolytic degradation was performed to force the drug substance to degradation by exposure of the drug to acidic, basic, and neutral conditions. The solubility of the drug substance was performed. The solubility of about $1 \mathrm{mg} / \mathrm{ml}$ of drug substance is recommended for hydrolytic degradation studies.

\section{Oxidative degradation}

Oxidative degradation promotes the reaction between drug substance and molecular oxygen in pharmaceutical formulations. In the study, peroxide-mediated oxidation studies are induced. The reaction of the oxygen with the drug substance is processed in the oxidative degradation.

\section{Photostability studies}

The photochemical stability of the drug was studied by exposing the UV Light by keeping the beaker in UV Chamber for $1 \mathrm{hr}$ or 200 Watt-hours $/ \mathrm{m}^{2}$ in photostability chamber.

\section{Thermal degradation studies}

Thermal degradation is also called as dry heat degradation studies. The drug substance or solution is placed in the oven at $105^{\circ} \mathrm{C}$ for $6 \mathrm{~h}$ to study the dry heat stability studies.

\section{Solution stability studies}

It is often essential that sample and standard solutions be stable enough to allow for delays covering the instrument breakdown or overnight analysis. A minimum of $12 \mathrm{~h}, 18 \mathrm{~h}$, and $24 \mathrm{~h}$ is recommended for chromatographic methods.

\section{RESULTS AND DISCUSSION}

\section{Method development}

Optimization of chromatographic separation

A number of chromatographic conditions were investigated to optimize the method of epalrestat and pregabalin in combination drug for the separation and quantification. The chromatographic conditions are shown in Table 1. 


\section{Calibration curve}

The correlation coefficient $\left(\mathrm{R}^{2}\right)$, slope, and y-intercept for epalrestat are $0.999,5603$, and 1248 and for pregabalin is $0.999,21487$, and 1936.3, respectively. The calibration curve is shown in Figs. 5 and 6.

\section{Method validation}

Linearity, accuracy, and precision

The correlation coefficient $\left(\mathrm{R}^{2}\right)$ for epalrestat and pregabalin was 0.999 as shown in Figs. 5 and 6. The accuracy of the method was indicated by the recovery. The results are shown in Table 2 . Intra- and inter-day precision HPLC data is shown in Tables 3 and 4.

\section{Assay}

The assay was performed to study the average mean peak area responses, $\mathrm{SD}, \% \mathrm{RSD}, \%$ assay and the amount was calculated as per label claim. The data is shown in Table 5.

\section{Robustness}

In the robustness study, the influence of small, deliberate variations of the analytical parameter on the retention time of drugs were examined.
The following three factors were selected for change: Flow rate of mobile phase $(1 \mathrm{ml} \pm 0.1 \mathrm{ml} / \mathrm{min})$, mobile phase composition $(45: 55 \pm$ $5 \%)$, and column temperature $\left(25^{\circ} \mathrm{C} \pm 10^{\circ} \mathrm{C}\right)$. There is an influence on retention times of the drug and RSD NMT $2 \%$ in modified condition. The data are shown in Tables 6-8.

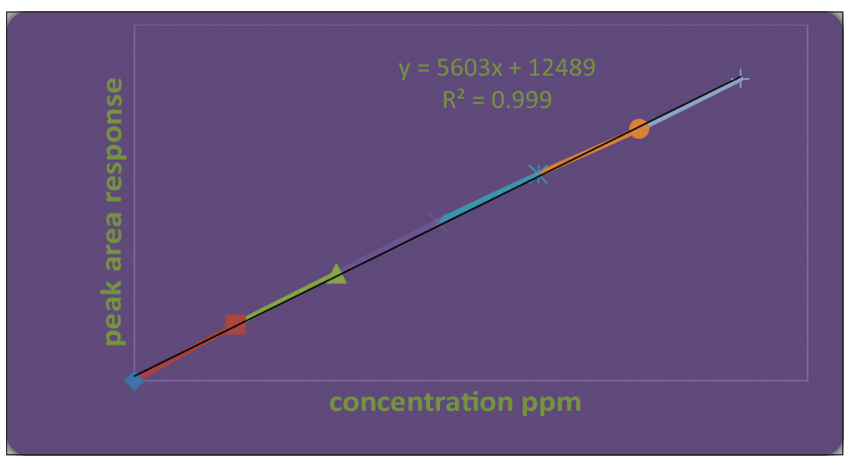

Fig. 5: Calibration curve of epalrestat

Table 2: Accuracy of epalrestat and pregabalin

\begin{tabular}{|c|c|c|c|c|c|c|c|c|c|}
\hline S. No. & Accuracy (\%) & $\begin{array}{l}\text { Amount } \\
\text { Added (mg) } \\
\text { epalrestat }\end{array}$ & $\begin{array}{l}\text { peak } \\
\text { area }\end{array}$ & $\begin{array}{l}\text { Amount } \\
\text { recovered }\end{array}$ & $\begin{array}{l}\% \\
\text { recovery }\end{array}$ & $\begin{array}{l}\text { Amount } \\
\text { added (mg) } \\
\text { pregabalin }\end{array}$ & $\begin{array}{l}\text { Peak } \\
\text { area }\end{array}$ & $\begin{array}{l}\text { Amount } \\
\text { recovered }\end{array}$ & $\begin{array}{l}\% \\
\text { recovery }\end{array}$ \\
\hline 1 & $50 \%$ & 224.0964 & 4293554 & 74.10 & 98.80 & 112.6604 & 244098 & 37.66 & 100.43 \\
\hline 2 & 50 & 223.6042 & 4284192 & 73.60 & 98.14 & 112.4443 & 2440098 & 37.66 & 100.43 \\
\hline 3 & 50 & 223.7951 & 4287822 & 73.80 & 98.39 & 111.8626 & 2422955 & 36.86 & 98.30 \\
\hline$\%$ RSD & & & 0.2 & & & & 0.1 & & \\
\hline 1 & 100 & 299.3885 & 5725685 & 149.39 & 99.59 & 149.4158 & 3229860 & 74.42 & 99.22 \\
\hline 3 & 100 & 300.0139 & 5737580 & 150.01 & 100.01 & 149.2038 & 3225306 & 74.20 & 98.94 \\
\hline$\%$ RSD & & & 0.3 & & & & 0.4 & & \\
\hline 1 & 150 & 371.7077 & 7101269 & 221.71 & 98.54 & 187.0608 & 4038738 & 112.06 & 99.61 \\
\hline 2 & 150 & 374.5049 & 7154473 & 224.50 & 99.78 & 187.1692 & 4038738 & 112.06 & 99.61 \\
\hline 3 & 150 & 375.2299 & 7168263 & 225.23 & 100.10 & 185.9601 & 4015088 & 110.96 & 98.63 \\
\hline$\%$ & & & 0.3 & & & & 0.2 & & \\
\hline RSD & & & & & & & & & \\
\hline
\end{tabular}

RSD: Relative standard deviation

Table 3: Intraday precision (repeatability) of epalrestat and pregabalin

\begin{tabular}{llll}
\hline Injection & Peak area response Epalrestat & USP tailing & Peak area response pregabalin \\
\hline 1 & 2972221 & 1.27 & 1654700 \\
2 & 2961113 & 1.28 & 1679004 \\
3 & 2957173 & 1.28 & 1676697 \\
4 & 2952700 & 1.28 & 1627790 \\
5 & 2935007 & 1.29 & 1636665 \\
6 & 2941183 & 1.29 & 1641180 \\
AVG & 2953233 & & 1652673 \\
SD & 13533.9 & & 21363.9 \\
$\%$ RSD & 0.5 & & 1.22 \\
\hline
\end{tabular}

RSD: Relative standard deviation

Table 4: Interday precision (ruggedness) of epalrestat and pregabalin

\begin{tabular}{llll}
\hline Injections & Peak area response epalrestat & USP tailing & Peak area response pregabalin \\
\hline 1 & 2866609 & 1.27 & 1691223 \\
2 & 2872405 & 1.28 & 1698723 \\
3 & 2876336 & 1.28 & 1700877 \\
4 & 2865846 & 1.28 & 1692801 \\
5 & 2859452 & 1.29 & 1691871 \\
6 & 2862096 & 1.29 & 1699207 \\
AVG & 2867124 & & 1695784 \\
SD & 6305.4 & & 4273.3 \\
\%RSD & 0.2 & & 0.3 \\
\hline
\end{tabular}

SD: Standard deviation, RSD: Relative standard deviation 


\section{Stability of solution}

Solution stability studies were performed to determine the stability of the samples the stability of the solution was above $24 \mathrm{~h}$.

Forced degradation studies

The assay method was used to test the drug stability by conducting forced degradation studies for the drug substances under various

Table 5: Assay of epalrestat and pregabalin

\begin{tabular}{llll}
\hline Drug & $\begin{array}{l}\text { Labeled } \\
\text { amount (Mg) }\end{array}$ & $\begin{array}{l}\text { Amount } \\
\text { Present (mg) }\end{array}$ & \% assay \\
\hline Epalrestat & 150 & 150.1 & 100.06 \\
Pregabalin & 75 & 75.17 & 100.22 \\
\hline
\end{tabular}

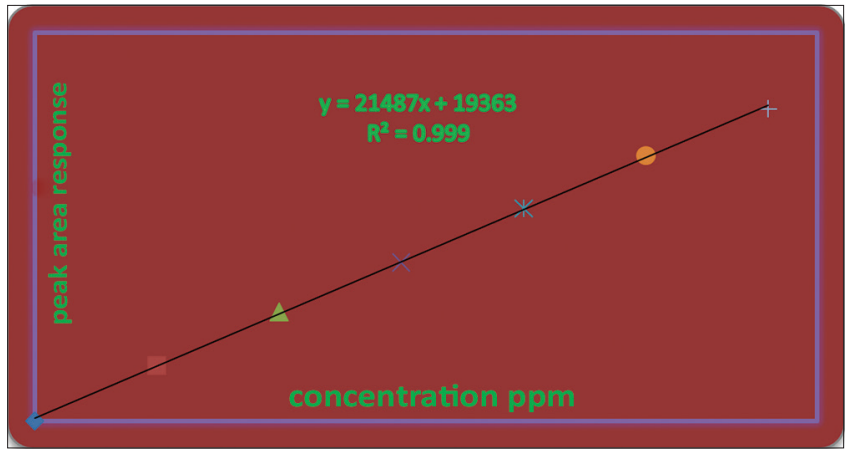

Fig. 6: Calibration curve of pregabalin

Table 6: Robustness flow rate

\begin{tabular}{|c|c|c|c|c|c|}
\hline S. No. & Flow rate $\mathrm{ml} / \mathrm{min}$ & Peak area epalrestat & RT epalrestat & Peak area pregabalin & RT pregabalin \\
\hline 1 & 1.0 & 2984889 & 2.840 & 1652175 & 2.281 \\
\hline 2 & 1.0 & 2972519 & 2.846 & 1650818 & 2.284 \\
\hline 3 & 1.0 & 2987793 & 2.848 & 1660292 & 2.286 \\
\hline \multirow[t]{2}{*}{$\%$ RSD } & & & 0.3 & & 0.2 \\
\hline & F.R plus & & & & \\
\hline 1 & 1.1 & 2676079 & 2.626 & 1524349 & 2.114 \\
\hline 2 & 1.1 & 2745802 & 2.627 & 1522711 & 2.114 \\
\hline 3 & 1.1 & 2741531 & 2.628 & 1522984 & 2.115 \\
\hline \multirow[t]{2}{*}{$\%$ RSD } & & & 1.4 & & 0.1 \\
\hline & F.R minus & & & & \\
\hline 1 & 0.9 & 3185153 & 3.102 & 1809701 & 2.490 \\
\hline 2 & 0.9 & 3157327 & 3.103 & 1802132 & 2.492 \\
\hline 3 & 0.9 & 3174303 & 3.104 & 1789056 & 2.493 \\
\hline$\%$ RSD & & & 0.4 & & 0.6 \\
\hline
\end{tabular}

RSD: Relative standard deviation

Table 7: Robustness mobile phase composition

\begin{tabular}{llllll}
\hline S. No. & Mobile phase composition & Peak area epalrestat & RT epalrestat & RT pregabalin & Peak area pregabalin \\
\hline 1 & $25: 75$ & 2984889 & 2.840 & 2.281 & 1652175 \\
2 & $25: 75$ & 2972519 & 2.846 & 2.284 & 1650818 \\
3 & $25: 75$ & 2987793 & 2.848 & 2.286 & 1660292 \\
\%RSD & & & & 0.3 \\
1 & M.P plus & & & & 1646502 \\
2 & $20: 80$ & 2873634 & 2.864 & 2.308 & 164489 \\
3 & $20: 80$ & 2869226 & 2.865 & 2.308 & 1654841 \\
$\%$ RSD & $20: 80$ & 2866199 & 2.865 & 2.310 & 0.3 \\
1 & M.P minus & 0.1 & & & 1660204 \\
2 & $30: 70$ & 2862445 & 2.822 & 2.264 & 1639353 \\
3 & $30: 70$ & 2896227 & 2.823 & 2.266 & 1645132 \\
$\%$ RSD & $30: 70$ & 2871237 & 2.825 & 2.268 & 0.7 \\
\hline
\end{tabular}

RSD: Relative standard deviation

Table 8: Robustness column temperature

\begin{tabular}{llllll}
\hline S. No. & Column temperature & Peak area epalrestat & RT epalrestat & RT pregabalin & Peak area Pregabalin \\
\hline 1 & $25^{\circ} \mathrm{C}$ & 2984889 & 2.840 & 2.281 & 1652175 \\
2 & $25^{\circ} \mathrm{C}$ & 2972519 & 2.846 & 2.284 & 1650818 \\
3 & $25^{\circ} \mathrm{C}$ & 2987793 & & 2.286 & 1660292 \\
$\% \mathrm{RSD}$ & & 0.1 & & & 0.2 \\
& $\mathrm{CT}$ plus & 2839155 & 2.842 & 2.283 & 1648639 \\
1 & $35^{\circ} \mathrm{C}$ & 2837300 & 2.843 & 2.285 & 1639881 \\
2 & $35^{\circ} \mathrm{C}$ & 2.845 & 2.287 & 0.3 \\
3 & $35^{\circ} \mathrm{C}$ & & & 1643426 \\
$\% \mathrm{RSD}$ & & 2824823 & 2.843 & 2.284 & 1636653 \\
1 & $\mathrm{CT}$ minus & 0.2 & 2.844 & 2.285 & 1637035 \\
2 & $15^{\circ} \mathrm{C}$ & 2828943 & 2.844 & & 0.2 \\
3 & $15^{\circ} \mathrm{C}$ & 2827738 & & & \\
$\% \mathrm{RSD}$ & $15^{\circ} \mathrm{C}$ & 2826567 & & & \\
\hline
\end{tabular}

RSD: Relative standard deviation 
Table 9: Forced degradation studies epalrestat and pregabalin

\begin{tabular}{|c|c|c|c|c|c|c|c|c|c|}
\hline S. No. & $\begin{array}{l}\text { Stress } \\
\text { conditions }\end{array}$ & $\begin{array}{l}\text { Peak area } \\
\text { epalrestat }\end{array}$ & $\begin{array}{l}\% \\
\text { Degraded }\end{array}$ & $\begin{array}{l}\text { Purity } \\
\text { angle }\end{array}$ & $\begin{array}{l}\text { Purity } \\
\text { threshold }\end{array}$ & $\begin{array}{l}\text { Peak area } \\
\text { pregabalin }\end{array}$ & $\begin{array}{l}\% \\
\text { Degraded }\end{array}$ & $\begin{array}{l}\text { Purity } \\
\text { angle }\end{array}$ & $\begin{array}{l}\text { Purity } \\
\text { threshold }\end{array}$ \\
\hline 1 & Control & 2981792 & 0.00 & 0.01192 & 1.092 & 1654819 & 00.00 & 0.097 & 1.112 \\
\hline 2 & Acid & 2849190 & 4.6 & 4.291 & 5.320 & 1654819 & 4.60 & 0.601 & 0.47 \\
\hline 3 & Alkali & 293655 & 2.82 & 0.721 & 0.854 & 1581908 & 2.79 & 0.671 & 0.709 \\
\hline 4 & Peroxide & 2939388 & 1.62 & 0.251 & 0.306 & 1611832 & 1.92 & 0.109 & 0.301 \\
\hline 5 & Thermal & 2969400 & 0.61 & 0.218 & 0.308 & 1626296 & 0.97 & 0.126 & 0.322 \\
\hline 6 & Photo stability & 2963754 & 0.80 & 0.229 & 0.307 & 1642113 & 0.96 & 0.116 & 0.304 \\
\hline
\end{tabular}

stress conditions. To detect a decrease in the amount of the active pharmaceutical ingredient present due to the degradation. Purity angle is less than Purity Threshold. The results are shown in Table 9. Degradation of epalrestat and pregabalin was more in acidic, alkali, and peroxide conditions it was less in thermal, photolytic, and neutral degradation. The degradation products produced did not interfere with epalrestat and pregabalin. Hence, the proposed method can consequently be regarded as stability-indicating. The data are shown in Table 9.

\section{CONCLUSION}

A new stability-indicating RP-HPLC method has been developed and validated for the simultaneous estimation of epalrestat and pregabalin in bulk and dosage forms. The method was validated as per ICH guidelines. Forced degradation studies were also conducted using different stress condition as per ICH guidelines. The method proved the selectivity, precision, accuracy, and mobile phase used to provide a simple and economic application. The method was capable to resolve the peak of selected drugs from stress degradation products. Consequently, the stability indicates the power of the method can be assessed. Therefore, the method was found to be suitable for the routine quality control analysis of epalrestat and pregabalin simultaneously in laboratories with no interference from the excipients or the stress degradation products. The developed method is simple, sensitive, rapid linear, precise, rugged specific, and robust.

\section{REFERENCES}

1. Epalrestat-Wikipedia. Available from: https://www.en.wikipedia.org/ wiki/Epalrestat.

2. Epalrestat-drugs.com. Available from: https://www.drugs.com/ international/epalrestat.html.

3. Lyrica, Pregabalin Side Effects (Weight Gain), Uses, and Dosing. Available from: http://www.medicinenet.com/pregabalin_lyrica/article. htm

4. Pregabalin-Drug Bank. Available from: https://www.drugbank.ca/ drugs/DB00230.

5. Pregabalin - NHS Beta. Available from: https://www.beta.nhs.uk/ medicines/pregabalin

6. Epalrestat/Drug Book. Available from: http://www.drugbook.in/ epalrestat.html.

7. Dhodi JB, Mestry SN, Juvekar AR. Diabetic nephropathy-genesis, prevention and treatment. Int J Pharm Pharm Sci 2014;6:42-7.

8. Rajesh KS, Dheeba B, Sampathkumar P, Sivakumar R. Proteomic analysis of human blood and urine in diabetic nephropathy. Int J Pharm Pharm Sci 2014;6:496-502.

10. Rajadhyaksha NG, Venkataswamy N. Efficacy, safety, and tole rability of epalrestat compared to methylcobalamine in patients with diabetic neuropathy. Int J Diabetes Dev Ctries 2009;29:28-34.

9. Harika BM, Prasad YR. Development and validation of stability indicating RP-HPLC method for the simultaneous estimation of Epalrestat and pregabalin in Bulk and pharmaceutical dosage form. Int J Pharm 2017;7:157-64.

11. Pathi PJ. The estimation of epalrestat in tablet dosage form by RPHPLC. Asian J Pharm Ana 2012;2:49-51.

12. Kasawar GB, Farooqui MN. Development and validation of HPLC method for the determination of pregabalin in capsules. Indian J Pharm Sci 2010;72:517-9.

13. Souri E, Eskandari M, Tehrani MB, Adib N, Ahmadkhaniha R. Hplc determination of pregabalin in bulk and pharmaceutical dosage forms after derivatization with 1-fluoro-2,4-dinitrobenzene. Asian J Chem 2013;25:7332-6.

14. Sneha P. Stability indicating assay method development and validation of pregabalin in pharmaceutical dosage forms by RPHPLC. Indo Am J Pharm Sci 2015;2:1038-47.

15. Bhatt KK, Patella EM. Simultaneous estimation of pregabalin and methylcobalamine in pharmaceutical formulaton by RP-HPLC. J Anal Bioanal Tech 2013;4:159.

16. Goday S, Rahaman SK, Rani AP. Forced degradation studies development and validation by RP-HPLC method for the simultaneous estimation of combination drugs elbasvir and grazoprevir in bulk and pharmaceutical dosage forms. Indo Am J Pharm Sci 2017;4:2526-33.

17. ICH. Q2 (R1) Validation of analytical procedures: Text and methodology. In: Proceedings of the International Conference on Harmonization, November; 1996.

18. ICH. Q1A (R2) Stability testing of new drug substances and products. In: Proceedings of the International Conference on Harmonization, November; 1996. 